\title{
OS IMPACTOS AMBIENTAIS PROVOCADOS PELA EXPLORAÇÃO EXCESSIVA DO CALCÁRIO LAMINADO NO MUNÍCIPIO DE NOVA OLINDA, CEARÁ
}

\author{
Natanael Alex Alves Pereira ${ }^{*}$ \\ a Universidade Regional do Cariri - URCA
}

\section{RESUMO}

O presente estudo estima identificar os impactos ambientais provocados pela exploração excessiva do Calcário Laminado, em Nova Olinda - Ceará. Por meio da observação das principais áreas de extração mineral e análise bibliográfica, foi possível apontar os maiores impactos ocasionados no município a partir dessa grande atividade econômica da região caririense. As atuais técnicas de exploração deste segmento, mostram-se um grande impasse quando nos referimos a um desenvolvimento sustentável e a preservação da biodiversidade e geodiversidade locais. Partindo dessas afirmações, sugerimos aqui um questionamento inicial, até que ponto a economia deve ser enfatizada como bem maior social? Fazer este questionamento é fundamental para este estudo, uma vez que nos possibilita mensurar, através de métodos comparativos, todas as facetas da problemática aqui proposta. Afinal esta é a essência e a prestabilidade da ciência, não apenas observar e descrever fatos, mas induzir a criticidade e possibilitar a descoberta de soluções aplicáveis.

\section{ABSTRACT}

This study intends to identify the environmental impacts caused by the excessive exploitation of Laminated Limestone, in Nova Olinda - Ceará. Through the observation of the main areas of mineral extraction and bibliographical analysis, it was possible to point out the greatest impacts caused in the municipality from this great economic activity in the Cariri region. The current exploration techniques in this segment are a major impasse when we refer to sustainable development and the preservation of local biodiversity and geodiversity. Based on these statements, we suggest an initial question here, to what extent should economics be emphasized as a greater social good? Asking this question is fundamental for this study, as it allows us to measure, through comparative methods, all facets of the problem proposed here. After all, this is the essence and helpfulness of science, not just observing and describing facts, but inducing criticality and enabling the discovery of applicable solutions.

Palavras-chave: Calcário Laminado; Extração Mineral; Impactos Ambientais; Nova Olinda

\footnotetext{
*Autor correspondente: Natanael Alex Alves Pereira. Graduado em Licenciatura Plena em Geografia; Nova Olinda CE; (88) 9 99271614; natanaelalex555@gmail.com

Editora IME@ 2021. Todos os direitos reservados.
} 


\section{INTRODUÇÃO}

É indubitável que a atividade explorativa de minerais no território brasileiro remonta o período colonial. A exploração do ouro como primícia dessa atividade econômica, aos poucos deu lugar a exploração de outros potenciais minérios encontrados nos solos brasileiros. Consequentemente este seguimento econômico cresceu sobremaneira e ganhou força frente as variadas atividades comerciais. Não restando dúvidas que contribuiu para o desenvolvimento industrial, comercial e consequentemente na movimentação de capital no país, proporcionando geração de empregos e estruturação de renda.

No entanto, o desenvolvimento e continuidade desse seguimento, sem nenhuma aplicabilidade de caráter sustentável, dá lugar ao surgimento de inúmeros impactos ambientais, que nos obrigam a repensar a essencialidade dessa atividade econômica. Ao que se refere aos impactos generalizados por tal atividade, Bacci, Landim e Eston (2006), afirmam que estes efeitos danosos a natureza, são observados em todas as fases da exploração, indo desde a abertura da cava até o transporte e beneficiamento do minério.

Indagar, repensar e reinventar nunca foram termos tão representativos quanto agora. Indagar sobre consequências generalizadas por tal prática, nos leva a um despertamento mister de que é fundamental repensar as práticas de exploração mineral no Brasil e reinventá-las, ao ponto de que seja possível alcançarmos o tão desejado desenvolvimento sustentável.

Devido ao seu elevado valor e aplicabilidade na construção civil, o Calcário Laminado passa a ser explorado a partir o século XIX, ganhando força e se desenvolvendo em demasia nos dias atuais, elevando o Cariri a um dos mais importantes polos minerais do Nordeste brasileiro. Os municípios de Nova Olinda e Santana do Cariri se destacam quando nos referimos a esta atividade mineradora, onde se estendem extensas áreas de exploração e onde é possível perceber, sem nenhuma parvidade os impactos decorrentes dessa prática. Deste seguimento pode-se destacar a exploração da Gipsita e do Calcário Laminado, mais comumente conhecido como Pedra Cariri, como as principais atividades extrativas da região. A Pedra Cariri é um calcário disposto em finas camadas de sedimentos pertencentes ao membro Crato (Formação Santana) depositados há aproximadamente 112 a 120 milhões de anos (período Cretáceo), quando neste local existia um lago de águas calmas, com brejos nas suas margens, onde uma Biodiversidade abundante se desenvolvia (LIMA et al., 2011).

De acordo com dados disponibilizados pelo Departamento Nacional de Produção Mineral (DNPM), estima-se que as jazidas do calcário possuem cerca de 97 milhões de metros cúbicos, podendo equivaler a aproximadamente 241 milhões de toneladas. A atividade pode render, somente em Nova Olinda, cerca de $\mathrm{R} \$ 12$ milhões para a economia local, por ano. Estes dados mostram o grande valor econômico desse seguimento, além de nos dar uma ideia de quantos metros cúbicos da Geodiversidade e Biodiversidade caririense serão completamente erradicados, frente a exploração excessiva e sem medidas sustentáveis.

A problemática aqui proposta precisa urgentemente ser mais difundida na comunidade científica, diálogos precisam ser encorajados, propostas sustentáveis precisam ser pensadas e aplicadas. Neste contexto a Educação Ambiental deve ganhar espaço sólido e contínuo, na busca da efetivação de técnicas que garantam a diminuição dos impactos ambientais nas áreas de exploração do Calcário Laminado, no município estudado. Pretende-se, portanto, observar e descrever, sem nenhum conflito de interesse, os principais impactos ambientais ocasionados pela exploração do Calcário Laminado, no município de Nova Olinda - Ceará. Considerando que a extração mineral se tornou uma das mais economicamente relevantes de toda a região do Cariri cearense. 


\section{MATERIAL E MÉTODOS}

O presente artigo se caracteriza como uma pesquisa de abordagem exploratória e de cunho qualitativo, que teve como principal intuito identificar os maiores impactos ambientais em algumas áreas de exploração mineral do município de Nova Olinda, Ceará. Nessa abordagem a pesquisa tem 0 ambiente como fonte direta dos dados. $\mathrm{O}$ pesquisador mantém contato direto com o ambiente e o objeto de estudo em questão, necessitando de um trabalho mais intensivo de campo (PRODANOV; FREITAS, 2013).

As pesquisas de campo se realizaram ao longo do mês de agosto de 2021, onde foram visitadas cinco áreas de mineração, na localidade do Sítio Pedra Branca, município de Nova Olinda, a aproximadamente $4 \mathrm{~km}$ da sede municipal. Os dados aqui apresentados foram obtidos a partir dos métodos de observação e aplicação de pequenas entrevistas com trabalhadores e donos das minas de exploração. As técnicas utilizadas para coletas de dados se mostraram exitosas, uma vez que permitiram a obtenção de informações relevantes para formulação da pesquisa. $\mathrm{Na}$ ocasião ainda foi realizada uma coleta dos registros fotográficos, que mostram alguns dos impactos mais comuns nas áreas estudadas.

Também foi realizado um levantamento bibliográfico prévio, de autores que abordam temáticas semelhantes, voltadas para os impactos ambientais decorrentes da exploração mineral excessiva, tanto no âmbito geral quanto local. Esta análise bibliográfica permitiu uma sólida formulação do embasamento teórico, garantindo informações complementares importantes sobre a temática. Foi possível perceber claramente a preocupação dos autores que tratam esta abordagem no município estudado, assim como a urgência para a aplicação de técnicas sustentáveis que garantam a sua coexistência junto dessa atividade econômica, visando um maior aproveitamento do material explorado e consequentemente uma brusca redução dos impactos nocivos ao meio ambiente.

\section{RESULTADOS E DISCUSSÕES}

Como já mencionado anteriormente, é correto afirmar que qualquer atividade econômica que vise a exploração de recursos naturais, acarreta consequentemente alguns impactos ambientais decorrentes. Considerando a relevante importância dessas atividades econômicas para as comunidades locais, surge então a necessidade de se trabalhar em recursos que diminuam estes impactos, ao ponto de que posteriormente seja possível uma recuperação das áreas de extração. Ao que se refere a atividade de mineração do Calcário Laminado, pode-se afirmar que não foge a esta regra, uma vez que as técnicas rudimentares aplicadas nessa exploração acabam contribuindo em demasia para a existência persistente de variados impactos (Tabela 1), que nesse capítulo serão abordados.

Em se tratando de características geológicas o município de Nova Olinda apresenta um quadro geológico onde predominam rochas do embasamento cristalino pré-cambriano, representadas majoritariamente por gnaisse e migmatitos diversos, quartzitos e meta calcário, associados a rochas plutônicas e metaplutônicas de composição predominantemente granítica. Sobre esse substrato repousam as sequências sedimentares da Bacia do Araripe, onde predominam na área algumas rochas da Formação Missão Velha, diversos afloramentos das Formações do Membro Santana e Formação Exu, em geral sendo constituídos por arenitos, aglomerados, siltitos, calcário, folhelhos, margas e gipsita. Portanto, as áreas possuem predominância de rochas sedimentares, terrenos constituídos predominantemente por rochas metamórficas e uma pequena cobertura sedimentar mais recente. No que se refere a Geomorfologia local, considerando que o município se localiza em uma área de deposição sedimentar, apresenta um relevo que varia das formas suaves e pouco dissecadas da Depressão Sertaneja a altitudes que podem chegar a 700 $\mathrm{m}$ acima do nível do mar, sendo representadas 
pela Chapada do Araripe.

No que se refere a formação do Calcário Laminado, o mesmo é um produto geológico decorrente das deposições sedimentares em paleoambiente lacustre, durante o Cretáceo Inferior. No fundo destes lagos de água salobra os estratos sedimentares, predominantemente carbonáticos, eram depositados de forma horizontalizada, favorecendo a compactação das partículas sedimentares e a atual estrutura em forma de bloco rochoso. Teoriza-se que constantes períodos climáticos secos favoreceram a desidratação destes ambientes, o que consequentemente proporcionou a cimentação dos sedimentos excedentes até a formação do atual material geológico estudado.

Entre os aspectos negativos dessa exploração, se destaca o desperdício do material geológico e o consequente entulhamento do mesmo, derivando alguns dos mais impactantes problemas ambientais que serão aqui descritos. O simples descarte no meio ambiente é uma prática ilegal, que pode gerar uma série de danos ambientais e danos à saúde humana. (MENEZES et al. 2010).

Nesse sentido, Moraes et al., (2020) destacam que:

A extração da Pedra Cariri é feita na maioria das vezes manualmente, causando grande perda de material. A retirada de material pode ser dividida em etapas: retirada do barro (solo orgânico em cima do calcário), feito este processo, retira-se uma capa (parte que não se aproveita); posteriormente procede-se com a extração, realização de limpeza e serragem do material. Dessa maneira, além de representar uma perda expressiva na produção de rochas ornamentais, os resíduos se apresentam como grandes causadores de impactos negativos ao meio ambiente. (MORAES et al. 2020).

Torna-se evidente que o minério está longe de ser completamente aproveitado nas localidades descritas. Ao longo das áreas de mineração é possível perceber os enormes morros entulhados de Calcário desperdiçado (Fig. 1), uma vez que, ainda se valoriza apenas o produto primário, que é o explorado/ preparado e destinado a construção civil. A prática de entulhamento desse rejeito é bem comum ao longo das áreas de mineração, ocasionando o desperdício e esgotamento do recurso natural, alteração da paisagem, modificação e destruição da vegetação, que provoca um desequilíbrio na distribuição geográfica da fauna nativa, intensificação dos processos erosivos e aumento dos riscos de acidentes de trabalho.

Figura 1: Morro entulhado de rejeito de Calcário Laminado. Sítio Pedra Branca, Nova Olinda, Ceará.

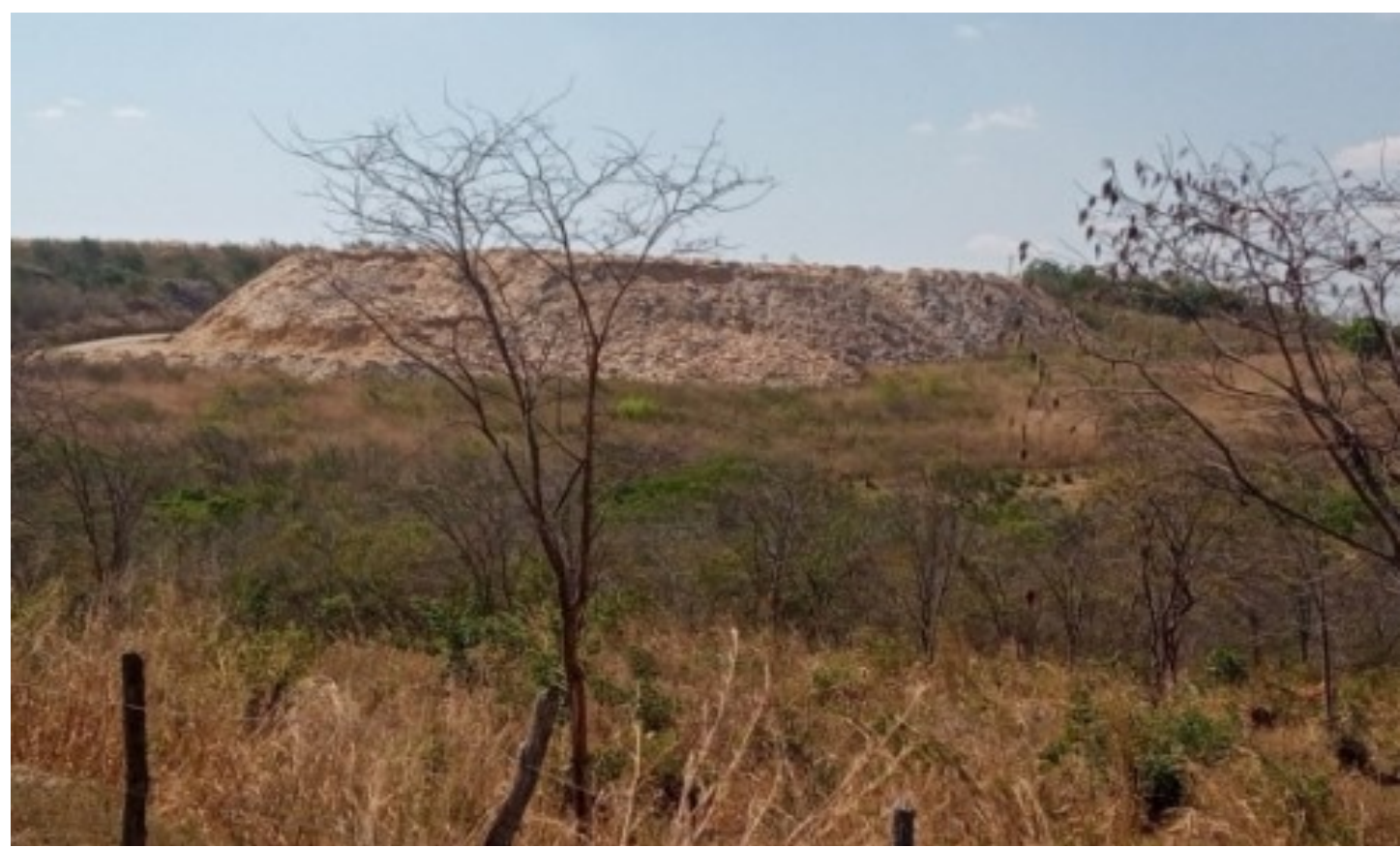

Natanael Pereira, agosto de 2021. 
No entanto, sabe-se que o rejeito deste minério pode ser reaproveitado na formulação de argamassa, na construção de blocos cerâmicos, na produção de trabalhos artesanais e até na correção da acidez do solo, servindo para fertilização e nutrição de algumas culturas agrícolas. Infelizmente os mineradores locais ainda acreditam ser desvantajoso economicamente, investir em qualquer outra atividade que não seja diretamente voltada para a exploração tradicional, de modo que as soluções descritas anteriormente para o excesso do rejeito mineral, são vistas como um investimento que pode não trazer o retorno financeiro desejado. Impossibilitando assim a aplicação e continuidade dessas técnicas de reaproveitamento do rejeito da Pedra Cariri.

Outro impacto visivelmente constante nestas áreas é a degradação do solo. O processo inicial desta exploração é a abertura da cava. Nessa etapa ocorre, em primeira instância, o desmatamento da vegetação nativa, seguida das escavações para retirada do solo que sobrepõe o capeamento estéril, que embora seja parte das jazidas de Calcário, não possui valor para o mercado de construção civil, por isso é completamente desperdiçado, só então a extração da Pedra Cariri comerciável é iniciada. Este processo inicial da mineração acaba provocando a erosão das encostas e áreas desmatadas e o assoreamento de riachos e do rio Cariús, principal rio da região. (CASTRO, CAMPOS \& VIDAL, 2007). Vale aqui ressaltar que essa retirada e movimentação de terra e do capeamento estéril causa ainda a alteração dos cursos hídricos intermitentes, que por sua vez também intensificam os processos intempéricos.

É sabido que a região se encontra em uma bacia sedimentar, a saber a Bacia Sedimentar do Araripe. Nessas formações geológicas os processos de intemperismo e erosão são constantes, já que atuam na deposição contínua de sedimentos no interior da bacia. Uma vez que estes processos naturais são intensificados pela exploração mineral, a degradação do solo sofre influência direta e também é intensificada a níveis devastadores como se vê.

Figura 2: Intensificação erosiva. Sítio Pedra Branca, Nova Olinda, Ceará. a- Mineração próximo a CE-166; b- Acostamento erodido.

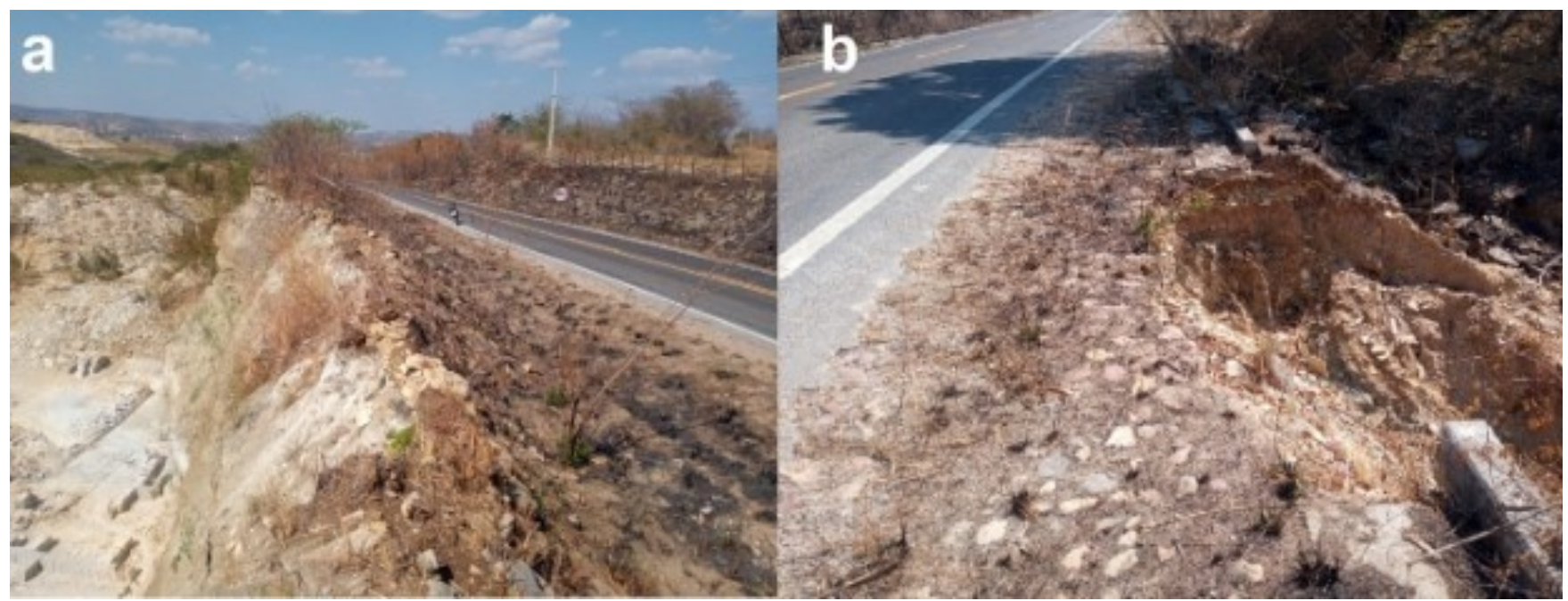

Fonte: Natanael Pereira, agosto de 2021. 
Como podemos observar na imagem (a), em algumas áreas as atividades de mineração começaram a avançar e se aproximar da Rodovia CE-166, que liga as cidades de Nova Olinda e Santana do Cariri, provocando a intensificação de processo intempéricos e erosivos. Ao analisarmos a imagem (b), percebemos diretamente a ação destes processos, pois uma grande parte do acostamento foi completamente desgastada e transportada pela ação da água. Além disso, esta aproximação ainda mostra-se um considerável perigo para as pessoas que utilizam diariamente a rodovia.

As imagens acima (Figura 2) foram coletadas a alguns metros do Geossítio Pedra Cariri, o que representa a grande evasão das áreas de mineração e dos seus impactos. Em suma, percebemos uma falta de conscientização e responsabilidade ambiental, que pode como consequência devastar toda uma riqueza geológica e paleontológica, sem nenhuma garantia de restauração. Nesse contexto, a responsabilidade ambiental é uma condição muito importante na luta pela preservação e diminuição de impactos. Nas atuais condições de uso do meio ambiente o papel constitucional e a aplicação de seus institutos tornam-se fundamentais (SILVA e RANGEL, 2019).

Por fim, a questão da erradicação do Patrimônio Paleontológico novo-olindense. Em se tratando da sua composição litológica o Membro Crato compõe-se de estratos horizontalizados de calcários, intercalados a folhelhos, siltitos e arenitos depositados durante o Cretáceo Inferior, há cerca de 120 milhões de anos (VIANA; NEUMANN, 2000). As camadas de Calcário Laminado apresentam uma enorme variedade de fósseis do Cretáceo Inferior, considerado por alguns pesquisadores como a maior concentração de registros paleontológicos dessa era geológica. (Fig. 3).

Figura 3: Fósseis encontrados nas áreas de mineração, em Nova Olinda, Ceará.

a- Fóssil de peixe; b- inseto; c- planta e inseto; d- asa de inseto; e- planta.

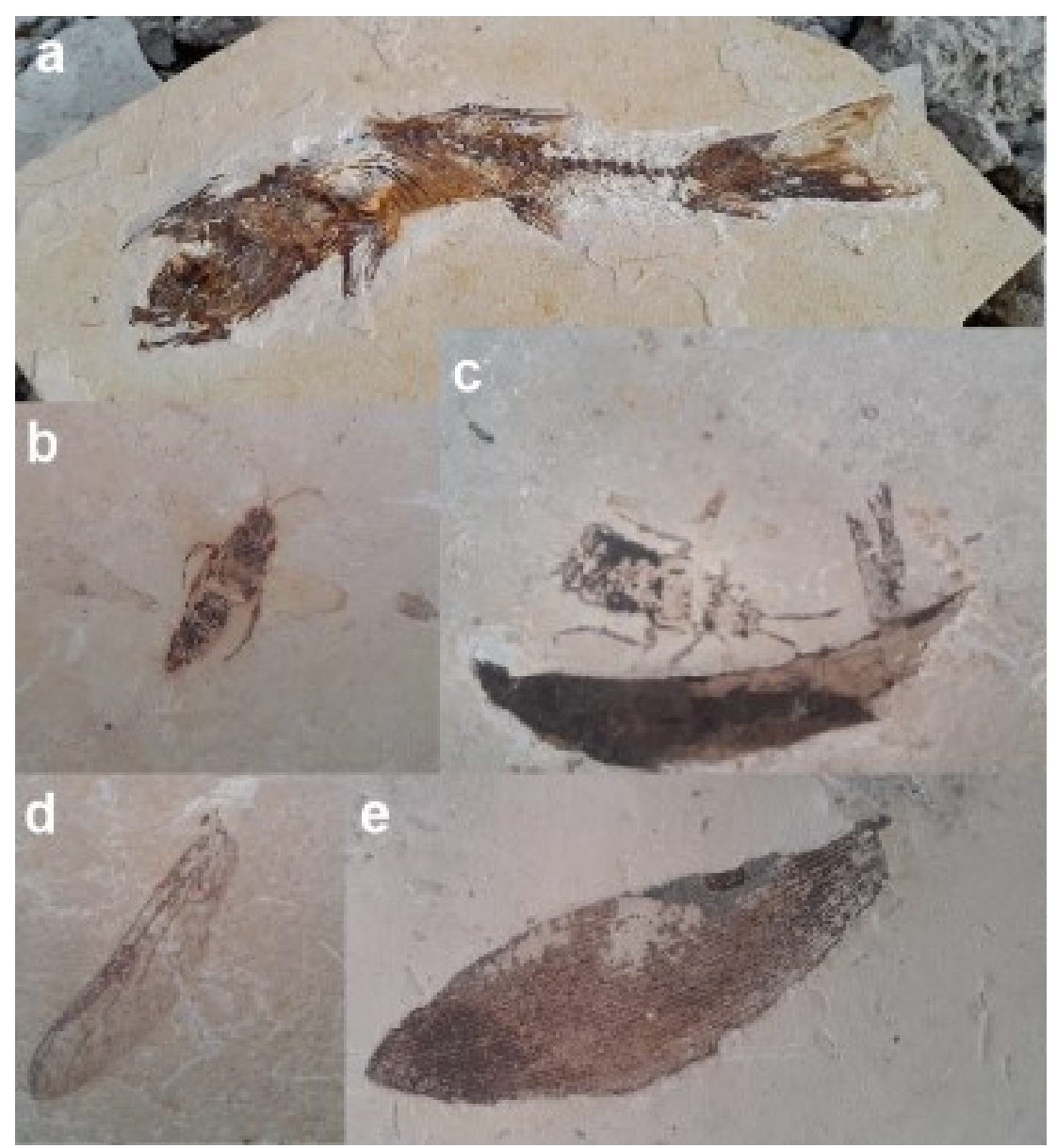

Fonte: Natanael Pereira, setembro de 2019. 
O registo fossilífero do Membro Crato é abundante e muito diversificado. Estão presentes cianobactérias (estromatólitos); foraminíferos; algas; fungos (esporos; hifas e micélios); plantas (avasculares e vasculares (gimnospermas e angiospermas); invertebrados moluscos (bivalves e gastrópodes), crustáceos (ostracodes, conchostráceos), aracnídeos, quilópodes, insetos; vertebrados (sarcopterígios, actinopterígios, destacando-se o Dastilbe elongatus (sinónimo júnior) / Dastilbe cardlli (sinónimo sénior) (atualmente, considerase válida apenas uma espécie Dastilbe crandalli (Romano, sd) anfíbios, répteis (pterossauros, quelónios, crocodilomorfos, lagartos); aves (algumas penas) e icnofósseis (coprólitos, rastros de invertebrados, pegadas) (VILAS BOAS, 2012, p. 40).

A notável presença desse vasto material paleontológico nas áreas de exploração do Calcário é outro fator que enaltece a necessidade de repensar as técnicas utilizadas. Durante o processo de extração do minério são encontrados inúmeros exemplares desse material de valor científico inestimável, infelizmente uma grande parte desse material é completamente destruído nesse processo, uma outra parcela fica exposta ao intemperismo junto com os entulhos dos rejeitos.

Nessa perspectiva, surge uma problemática ainda maior, o tráfico de fósseis tornou-se constante nas mineradoras. Os trabalhadores locais enxergam nessa prática ilegal um meio de garantir uma renda extra, desse modo é atribuído apenas o valor econômico dessas peças, sendo completamente excluído o seu valor científico e patrimonial. Boa parte dos fósseis da região é um subproduto da atividade extrativa já mencionada, no entanto, são poucos os proprietários das pedreiras que proíbem os trabalhadores de recolherem os fósseis para posterior venda (VILAS BOAS, 2012). Neste sentido, Pereira (2019), ressalta que:

Entre os principais fatores que possibilitam esse comércio ilegal se destacam: A vasta ocorrência de fósseis, em parte resultado da atividade extrativa, o baixo nível salarial dos trabalhadores das pedreiras que encaram a atividade ilegal como complemento de renda, a deficiente fiscalização e controle por parte do DNPM e das forças policiais, a reduzida conscientização social sobre o real significado e valor patrimonial dos fósseis, a sua relevância científica e estética e seu elevado valor econômico. (PEREIRA, 2019, p. 31).

Percebe-se aqui uma urgência na construção de uma conscientização social voltada para o tráfico de fósseis no município de Nova Olinda. Essa prática desvaloriza o patrimônio natural e contribui para sua erradicação. Alguns projetos sociais já foram desenvolvidos visando a proteção e salvaguarda desse material paleontológico, mas infelizmente não tiveram espaço necessário para continuidade e desenvolvimento.

Desenvolver projetos sociais de caráter educacional tem se mostrado a resposta imediata para a grande maioria dos problemas socioambientais da contemporaneidade, pois conscientizar sempre será mais efetivo que proibir. Levando em consideração a importância em trabalhar a geodiversidade, tanto no ensino escolar quanto fora do ambiente educacional, torna-se fundamental estabelecer e desenvolver o conceito científico de Geoeducação, sendo esse um ramo da educação ambiental que pode ser aplicado na Geoconservação do patrimônio natural. (Moura-Fé et al. 2016).

Surge então uma grande possibilidade de sucesso, quando nos referíamos a valorização e proteção desses patrimônios geológicos e paleontológicos novo-olindense, assim como da biodiversidade local. A aplicação desses conceitos educacionais embasados na Educação ambiental, mostra-se uma ótima proposta a ser considerada, frente os variados impactos resultantes da exploração excessiva do Calcário Laminado. (Tabela 1). 
Tabela 1: Impactos resultantes da exploração do Calcário Laminado, em Nova Olinda, Ceará.

\begin{tabular}{|c|c|}
\hline $\begin{array}{c}\text { E tapas de Exploração do Calcário } \\
\text { Laminado }\end{array}$ & Impactos Decorrentes \\
\hline Abertura da Cava & $\begin{array}{l}\text { Desmatam ento de vegetação nativa } \\
\text { Modificação da pai sagem } \\
\text { Afugentam ento da fauna nativa } \\
\text { Poluição sonora } \\
\text { Degradação do solo } \\
\text { Intensificação de processos intempéricos e erosivos } \\
\text { Assoream ento e alteração de cursos hidricos } \\
\text { Comprometimento das águas superficiais }\end{array}$ \\
\hline Ex tração e Preparo da Pedra Cariri & $\begin{array}{l}\text { Geração de poeira } \\
\text { Poluição sonora } \\
\text { Exposição a acidentes de trabalho } \\
\text { Esgotamento de recur so natural } \\
\text { Destruição do patrim ônio fossilifero } \\
\text { Indução ao tráfico de fósseis }\end{array}$ \\
\hline Abertura de Novas Vias de Acesso & $\begin{array}{l}\text { Intensificação de processos intempéricos e erosivos } \\
\text { Assoream ento e alteração de cursos hidricos } \\
\text { Destruição do patrim ônio fossilifero } \\
\text { Poluição sonora } \\
\text { Geração de poeira }\end{array}$ \\
\hline Entulhamento de Rejeitos & $\begin{array}{l}\text { Desperdicio e esgotamento do recurso natural Alter ação da } \\
\text { paisagem } \\
\text { Modificação e destruição da vegetação } \\
\text { Afugentamento da fauna nativa } \\
\text { Intensificação dos processos er osivos } \\
\text { Exposição a acidentes de trabalho }\end{array}$ \\
\hline Transporte de Material Explorado & $\begin{array}{l}\text { Desperdicio de material } \\
\text { Geração de poeira } \\
\text { Exposição a acidentes de trabalho }\end{array}$ \\
\hline
\end{tabular}

Fonte: Autoria própria do autor

Ao analisarmos a tabela 1, é possível percebermos claramente a quantidade massiva de impactos deferidos ao ambiente local, o que reforça a necessidade de questionar a importância da continuidade dessa prática extrativa, completamente despreocupada para com os cuidados ambientais necessários à sua preservação. Nota-se que já na primeira etapa de exploração os impactos são notadamente marcantes e diretos à fauna, flora e ao solo. A continuidade dessa exploração excessiva permite aqui estimar, em um futuro não tão distante, cerca de 97 milhões de metros cúbicos do Cariri cearense completamente devastados.

\section{CONCLUSÃO}

Diante de todo o exposto, não restam dúvidas que a atividade econômica estudada, a saber a exploração mineral do Calcário Laminado na localidade do Sítio Pedra Branca, município de Nova Olinda - Ceará, resulta nestes variados impactos socioambientais descritos. E embora essa atividade represente um grande valor socioeconômico para toda a região do Cariri cearense, ela contrasta diretamente com esta vasta gama de problemáticas.

O simples fato do município de Nova Olinda se localizar dentro do território do Geopark Araripe, já expressa a necessidade da existência de um desenvolvimento sustentável regional, sendo essa a consumação prática e funcional de um Geoparque. Sabe-se que nessas áreas protegidas o patrimônio primeiro valorizado é o geológico, visando justamente a sua conservação. Não se pode esquecer que 
devido ao seu elevado valor científico as jazidas de Calcário Laminado novo-olindenses possuem um geossítio em suas proximidades, - Geossítio Pedra Cariri, o que eleva ainda mais os seus valores ecológico, turístico, cultural e educativo.

O presente trabalho busca afirmar que a continuidade dessa exploração excessiva, resulta na perca definitiva desses patrimônios, sendo, portanto, necessária a apropriação social de ações que diminuam estes impactos. A hora de repensar e reinventar chegou, na verdade nunca foi tão urgente quanto agora, difundir a preocupação voltada para a erradicação desses patrimônios. A necessidade de desenvolvimento dessa conscientização social se expressa em cada ação antrópica que ameaça a existência da biodiversidade e geodiversidade únicas da região do Cariri.

\section{REFERÊNCIAS}

BACCI, D. L. C.; LANDIM, P. M. B.; ESTON, S. M. Aspectos e impactos ambientais de pedreira em área urbana. Ouro Preto, 59(1): 47-54, jan. mar. 2006.

CASTRO, N. F.; CAMPOS, A. R.; VIDAL, F. W. H. Melhoras técnicas na lavra e na proteção do patrimônio e meio ambiente do Arranjo Produtivo Local de Calcários do Cariri CE. In: I Jornada do Programa de Capacitação Institucional, CETEM, Rio de Janeiro, RJ. Resumos expandidos, p. 21-25, 2007.

MENEZES, R. R; MELO. L. R. L; FONSÊCA, F. A. S; SOUTO, P. M; NEVES, G. A; SANTANA, L. N. L. Reciclagem do resíduo da serragem de calcário laminado para produção de blocos cerâmicos. Ouro Preto, out. dez. 2010.

MORAES, A. H. M; OLIVEIRA, J. F. A; MARINHO, J. L. A; JANUÁRIO, T. L. S. Análise Ambiental das Atividades de Mineração da Pedra Cariri no Município de Nova Olinda - CE. Revista Gestão e Sustentabilidade Ambiental. Florianópolis, v. 9, n. 2, p. 57-73, abr/jun. 2020.
MOURA-FÉ, M. M. de et al. GEOEDUCAÇÃO: A EDUCAÇÃO AMBIENTAL APLICADA NA GEOCONSERVAÇÃO. in: Educação Ambiental \& Biogeografia, Giovanni Seabra (org.), Ituiutaba, v. 2, p.829842, 2016.

LIMA, F. F. et al. Geopark Araripe: histórias da terra, do meio ambiente e da cultura. Crato - CE, 2011.

PEREIRA, N. A. A. As Abordagens da Paleontologia na Escola Padre Luis Filgueiras (Nova Olinda, Ceará). Monografia (Graduação) - Curso de Licenciatura Plena em Geografia, Universidade Regional do Cariri. 2019.

PRODANOV, C. C; FREITAS, E. C Metodologia do Trabalho Científico: Métodos e Técnicas da Pesquisa e do Trabalho Acadêmico - $2^{a}$ Edição. 2. ed. Novo Hamburgo: Editora Feevale, 2013. v. 1. 276 p.

SILVA, D. C.; RANGEL, T. L. V. Impactos Ambientais Causados Pela Mineração. In: III Seminário Ensino, Pesquisa \& Cidadania em Convergência. 2019. v. 4. p. 43-50.

VIANA, M. S. S.; NEUMANNN, V. H. O Membro Crato da Formação Santana. In: Carlos Schobbenhaus. (Org.). Sítios Geológicos e Paleontológicos do Brasil. Brasília, 2000.

VILAS BOAS, M. P. Património paleontológico do Geopark Araripe (Ceará, Brasil): análise e propostas de conservação. 2012. 196 f. Dissertação (Mestrado) - Curso de Mestrado em Património Geológico e Geoconservação, Universidade do Minho, 2012. 